\title{
Unlocking the Quest for Artificial Wisdom as Integration of Artificial Intelligence with Desire
}

\author{
Aloke Sarkar ${ }^{1,2}$ \\ ${ }^{1}$ Electronics \& Communication Engg., Computer Engg. Associate Member of Institution of Engineers (India), Kolkata, India \\ ${ }^{2}$ Steel Authority of India Limited, Rourkela Steel Plant, Rourkela, India \\ Email address: \\ alokesarkar@hotmail.com \\ To cite this article: \\ Aloke Sarkar. Unlocking the Quest for Artificial Wisdom as Integration of Artificial Intelligence with Desire. Science Research. \\ Vol. 3, No. 3, 2015, pp. 79-88. doi: 10.11648/j.sr.20150303.16
}

\begin{abstract}
Wisdom $=$ Knowledge + Desire . Desire $=$ Need - Knowledge of Self - Unbiased Reasoning. Wisdom is the process of dynamic correlations among knowledge quanta (KQ), and desire quanta to generate new knowledge, and desire quanta, that in turn generates new propositions as priori, or, counterbalanced, or self-presenting to have 'true belief de re' to enable belief without sufficient evidence or dis-belief with sufficient evidence. Dynamic correlation procedure is the use of generalizability thesis (GZT) to synthesize inside intelligence improvement loop (IIL). The collection of data, creation of information, crashing of information to KQ and conceiving of KQ in long term memory (LTM) on generation of explicit links to other KQs those are already in existence and subsequent generation of wisdom module to be collected as data is termed as IIL. We may define artificial wisdom (AW) as integration of artificial intelligence (AI) with desire. AI is the p proposition of GZT, desire is the $\mathrm{q}$ proposition, and $r$ is the integration operator (INO). Thinking and creation is manifestation of dynamic correlation of desire with knowledge. INO should have two parts - integration process (IP) and integration rules (IR). IP will be the set of propositions to effect the AI to satisfy needs. IP always follows IR to fulfill the growth needs. As per IIL the set of rules or algorithms are the scholar's capability to reference different KQ simultaneously. The edge of discovery comes from the effectiveness of the parallel processing activities of the multiprocessor environment that again in turn depends on the rules and algorithms defined with propositional knowledge. The thinking capability of AW is to be branched out in 'mutually exclusive and/or inclusive' hardware and software standardizations. The term 'mutually exclusive and/or inclusive' refers a multiprocessor parallel processing system, with simplified linking and loading scheme to work in real time. That is a machine that can behave, think like a human and be trained or else upgraded with very simple instruction sets. This seems to be easier if there is a hardware interpreter for high-level language. It is interpreter because while referencing a KQ for any (possible) remark, KQ will interpret only the present information (focal knowledge with respect to the comprehensive whole for which it is called for).
\end{abstract}

Keywords: Artificial Wisdom, Artificial Intelligence, Desire, Need, Dynamic Correlations, Generalizability Thesis, High-Level Hardware Interpreter

\section{Introduction}

Artificial Wisdom (AW) is a quest since time immemorial. AW can create, and invent. It can replace human. The difference between wisdom and intelligence is that you cannot be wise unless you have sensitivity for the human condition [22].The emotional intelligence is specific to human. Each human starts with a background of knowledge that comes from her/his socio-biological-psychological background and develops own wisdom in a time dependent frame. $\mathrm{AI}$ is designed on the basis of some axioms, but $\mathrm{AW}$ will have to be designed on the basis of axiomatic propositions in time dependent frame. AI is posteriori, but AW comes with priori. AW will generate axioms on its own. To generate AW, we first have to realize and define the wisdom of human beings. Where is the starting point of this codification? We the human beings are social elements. We organize ourselves in organizations -- family, social, professional and so on. This organization is our arrangements in complex groups. These groups are also interconnected and interacting. One's membership in a group is either by self-interest, or by other's interests, or by force, or by consequences of membership in other group, or combination 
of these. So to codify our wisdom the starting point should be the organization. In organizations we share our knowledge using wisdom as tool.

\section{Organization \& Wisdom}

Organizations exist because of their ability to create value and acceptable outcomes for various groups of stakeholders, people who have an interest, claim, or stake in the organization, in what it does, and in how well it performs [9]. Stakeholders are motivated to participate in an organization if they receive inducements (rewards - money, power, status etc.) that exceed the value of the contributions (skills, knowledge and expertise) they are required to make. So an organization can be viewed as the integration of behavior variability of stakeholders - suppliers, customers, employees, managers, government, unions, community and general public [23]. Through knowledge-based view [21] of the firm (the firm is seen primarily as a vehicle for creating, integrating, storing and applying knowledge) a knowledge strategy is build on knowledge-based SWOT analysis (strength, weakness, opportunities and threats). As per [28] business strategy should be viewed less as a quest for monopoly rents (the return to market power) and more as a quest for Ricardian rents (the returns to the resources which confer competitive advantage over and above the real costs of these resources). The competitive advantage comes from cost advantage (process technology, size of plant, access to low-cost inputs) and differential advantage (brands, product technology, marketing-distribution-service capabilities).

Wisdom may now be called as integration of knowledge and need in a context free regime or in a broad context regime to have the Ricardian rents. AW may now be differentiated from AI as a vehicle that can create not only as per need but also future need. AI is based on axioms, but AW may change and/or create axiom. We start from differentiating knowledge from wisdom, defining wisdom, process of wisdom creation, software and hardware requirements.

\section{Data Information Knowledge Wisdom Ramp}

Data is unstructured raw material that does not convey any meaning to its recipient. Information is structured data that conveys some sort of meaning to its recipient. Knowledge is crashed information in particular context. Wisdom is conceived knowledge that allows application of information to a context other than the context in which knowledge is formed. As per [31] data arrive at our lives and on our desks as dispersed elements. It is only when we compile this data into a meaningful pattern that we have information. As information is converted into a valid basis for action, it becomes knowledge. Upon achieving wisdom we implicitly know how to generate, access, and integrate knowledge as a guide for action. As individuals and organizations move through the constructs from data to wisdom, their depth of meaning increases and their interpretation shifts from being highly explicit at data stage to entirely tacit at the point of wisdom.

Explicit knowledge is articulated knowledge - the words we speak, the books we read, the reports we write, the data we compile. Tacit knowledge is unarticulated - the intuition, perspectives, beliefs, and values that people form as a result of their experiences. The distinction between tacit knowledge and explicit knowledge has sometimes been expressed in terms of knowing-how and knowing-that, respectively, or in terms of a corresponding distinction between embodied knowledge and theoretical knowledge. Knowing-how is characteristic of the expert, who acts, makes judgments, and so forth without explicitly reflecting on the principles or rules involved. Knowing-that, by contrast, involves consciously accessible knowledge that can be articulated and is characteristic of the person learning a skill through explicit instruction, recitation of rules, attention to his or her movements, etc.

\section{Wisdom}

As per [31] wisdom is the tacit knowledge set. It has highest depth of meaning but least source of interpretation. Philosophers have defined three types of knowledge [37]: (1) acquaintance knowledge consists in first-hand acquaintance with a person, a place, an event and so on; (2) ability knowledge consists in knowing how to perform various actions and (3) propositional knowledge is a special relationship between a person and a true proposition. We may say that this special relationship is wisdom.

If the information is true and the acceptance of it is objectively justified, it amounts to knowledge. Knowledge is the outcome of critical inquiry, it is what emerges, or at least would emerge, from the crucible dialectical engagement with objection [20].

It is information that we recognize to be correct that yields the characteristically human sort of knowledge that distinguishes us as adult cognizers from, other animals, and even our infant selves. Information recognized as correct is inextricably woven into reasoning, justification, confirmation and refutation [17].

One can either believe, or disbelieve, or withhold (not believing $\mathrm{h}$ and not believing not-h), with respect to time any proposition. The withholding with respect to time and prediction of possibility to believe or disbelieve is the task of intelligence. If this intelligence takes the socio-psychological factors, wisdom comes. Wisdom is the truth value with socio-psychological considerations of a proposition that is the aggregate of knowledge or else reality and desire.

E1.1: WISDOM $=$ TRUTH $=$ KNOWLEDGE + DESIRE $=$ REALITY + DESIRE;

E1.2: TRUTH $=$ TRUTH OF ACTION + TRUTH OF INACTION + TRUTH OF PROHIBITED ACTION;

E1.3: DESIRE $=$ SENSE + MIND + INTELLECT KNOWLEDGE OF SELF - UNBIASED (shaking off attachments) REASONING; (Courtesy:[45] 4.38, 3.38 -3.43) 


\subsection{Knowledge vs. Wisdom}

To generate artificial wisdom (AW), it must be differentiated from artificial intelligence (AI) or else knowledge. This differentiation requires inclusion of 'desire'. This requires reasoning, justification, confirmation, and refutation. For these, we are referring [6].

D1.1: $h$ is beyond reasonable doubt for $\mathrm{S}$ if accepting $\mathrm{h}$ is more reasonable for $\mathrm{S}$ than is withholding $\mathrm{h}$.

D1.2: $\mathrm{h}$ has some presumption in its favor for $\mathrm{S}$ if accepting $\mathrm{h}$ is more reasonable for $\mathrm{S}$ than accepting not-h.

Note1: Beyond reasonable doubt implies some presumption, but reverse is not true.

D1.3: $\mathrm{h}$ is acceptable for $\mathrm{S}$ if 'withholding' is not more reasonable for $\mathrm{S}$ than accepting $\mathrm{h}$.

Note 2 [1, pp 40]: If a person accepts that $\mathrm{p}$, then the person will be ready to affirm that $p$ or to concede that $p$ in appropriate circumstances and use $p$ to justify other conclusions.

Note 3 [18]: Epistemic Acceptance - If S knows that $p$ then $\mathrm{S}$ accepts that $\mathrm{p}$ with the objective of accepting all and only what is true.

Note 4: Wisdom seeks doubts in acceptable proposition, that is the first step towards invention or discovery.

$D 1.4$ : $h$ is certain for $S$ if $h$ is beyond reasonable doubt for $S$, and there is no $i$ such that accepting $i$ is more reasonable for $\mathrm{S}$ than accepting $h$.

Note 5: Wisdom reasons on seeking doubts to define certainty in time dependent frame. The doubt is outcome of the desire.

D1.5: $h$ is evident for $S$ if (i) $h$ is beyond reasonable doubt for $\mathrm{S}$ and (ii) for every $\mathrm{i}$, if accepting $\mathrm{i}$ is more reasonable for $\mathrm{S}$ than accepting $h$, then $i$ is certain for $S$.

Note 6: Absolute certain implies evident, but reverse is not true. Intelligence can work with evident but fails in counterbalanced situation where wisdom comes to solve.

D1.6: $\mathrm{h}$ is counterbalanced for $\mathrm{S}$ if accepting $\mathrm{h}$ is not more reasonable for $\mathrm{S}$ than accepting not-h, and accepting not-h is not more reasonable for $\mathrm{S}$ than accepting $\mathrm{h}$.

Note 7: In the process of creation the stalemate comes often. Wisdom solves it on describing 'truth of inaction' and 'truth of prohibited action' properly with 'desire.' To describe wisdom uses GZT and IIL.

Note 8: If believing I is preferable to believing $\mathrm{h}$ and also preferable to believing not- $h$, then withholding $h$ is preferable to withholding I, and withholding $\mathrm{h}$ is the same as withholding not-h.

Note 9: Intelligence is the intersection of 'known truth' and 'tendency to avoid error.' [6]

$\mathrm{D} 2.1 \mathrm{~h}$ is self-presenting for $\mathrm{S}$ at $\mathrm{t}$ if $\mathrm{h}$ occurs at $\mathrm{t}$; and necessarily, if $h$ occurs at $t, h$ is evident for $S$ at $t$.

$\mathrm{D} 2.2$ : $\mathrm{h}$ is directly evident for $\mathrm{S}$ if $\mathrm{h}$ is logically contingent; and there is an e such that (i) e is self-presenting for $\mathrm{S}$ and (ii) necessarily, whoever accepts e accepts $h$.

Note 10: The expression " $h$ is logically contingent" abbreviates "It is false that $\mathrm{h}$ is necessarily such that it occurs and it is also false that $\mathrm{h}$ is necessarily such that it does not occurs." In situation of logical contingency intelligences seeks directly evident whereas wisdom can work with self-presenting. Self-presenting is time variable with acceptability by the subject.

D3.1: $h$ is an axiom if $h$ is necessarily such that (i) it is true and (ii) for every $S$, if $S$ accepts $h, h$ is certain for $S$.

D3.2: $h$ is axiomatic for $\mathrm{S}$ if (i) $\mathrm{h}$ is an axiom and (ii) $\mathrm{S}$ accepts $h$.

Note 11: An axiom or Basic truth is a proposition "which has no other proposition prior to it." Axiom and axiomatic may be confusing as they has certain factor (D1.4). Axiom is certain but axiomatic are not certain for all time and persons.

Any conjunction of axioms is itself an axiom. But any conjunction of axiomatic propositions for a subject may not be axiomatic. AI is designed on axioms, but AW will take axioms as axiomatic in time dependent frames.

D3.3: $\mathrm{h}$ is known a priori by $\mathrm{S}$ if there is an e such that (i) e is axiomatic for $\mathrm{S}$, (ii) the proposition, e implies $\mathrm{h}$, is axiomatic for $\mathrm{S}$, and (iii) $\mathrm{S}$ accepts $\mathrm{h}$.

D3.4: $\mathrm{h}$ is priori if it is possible that there is someone for whom $\mathrm{h}$ is a priori.

Note 12: A priori is evident but need not be certain. A priori proposition begins with experience, whereas a posteriori arise out of experience. In decision making in odd situation, intelligence seeks for axiomatic on the basis of posteriori. Wisdom takes priori to create.

D4.1: e tends to confirm h: Necessarily, for every S, if either (a) e is evident for $\mathrm{S}$ and such that everything that is evident for $\mathrm{S}$ is entailed by e or (b) e is indirectly evident for $\mathrm{S}$ and such that everything that is indirectly evident for $\mathrm{S}$ is entailed by $\mathrm{e}$, then $\mathrm{h}$ has some presumption in its favor for $\mathrm{S}$.

Note 13: The expression "e is indirectly evident for S" may here be taken to abbreviate " $h$ is evident for $\mathrm{S}$ but neither directly evident nor a priori for S".

D4.2: $\mathrm{i}$ defeats the confirmation that e tends to provide for $\mathrm{h}$ if (i) e tends to confirm $\mathrm{h}$, and (ii) the conjunction, e and i, does not tend to confirm $h$.

D4.3: $\mathrm{S}$ believes without ground for doubt, that $\mathrm{p}$ if (i) $\mathrm{S}$ believes that $\mathrm{p}$ and (ii) no conjunction of propositions that are acceptable for $\mathrm{S}$ tends to confirm the negation of the proposition that $\mathrm{p}$.

Note 14: Principle of Evidence: For any subject $S$, if $S$ believes without ground for doubt, that he is perceiving something to be $\mathrm{F}$, then it is beyond reasonable doubt for $\mathrm{S}$ that she perceives something to be F. Intelligence believes without ground for doubt all axioms. Wisdom accepts axioms as a set of 'concurrent propositions' that may need further confirmation. [6]

D4.4: $\mathrm{A}$ is a set of concurrent propositions if $\mathrm{A}$ is a set of two or more propositions each of which is such that the conjunction of all the others tends to confirm it and is logically independent of it.

D4.5: e entails $h$ if e is necessarily such that (i) if it obtains then $h$ obtains and (ii) whoever accepts it accepts $h$. 
Table 1. Propositional knowledge.

\begin{tabular}{llll}
\hline No & KNOWLEDGE (is) & WISDOM (is) & Reference \\
\hline $\mathrm{T} 1.1$ & Certain & Acceptable & E1.1, D1.1- D1.4, Note 1-5 \\
$\mathrm{T} 1.2$ & Evident & Counterbalanced & D1.5-D1.7, Note6-8 \\
$\mathrm{T} 1.3$ & Directly evident & Self-presenting & D2.1-2.2, Note9-10 \\
$\mathrm{T} 1.4$ & Axiomatic & Priori & D3.1-3.2, Note11-12 \\
& & Tends to conform & \\
$\mathrm{T} 1.5$ & Belief without doubt & Defeats & D4.1-4.6, Note13-14 \\
& & A set of Concurrent Proposition & \\
$\mathrm{T} 1.6$ & True belief de dicto & True belief de re & D5.5-5.6, D6.1-6.6, Note 16-21 \\
$\mathrm{T} 1.7$ & Nondefectively evident & More probability than not & E1.1, D1.1- D1.4, Note 1-5 \\
$\mathrm{T} 1.8$ & Context sensitive & Context free & D1.5-D1.7, Note6-8 \\
\hline
\end{tabular}

D4.6: e is logically independent of $\mathrm{h}$ if $\mathrm{e}$ is such that (i) it does not entail $h$, (ii) it does not entail the negation of $h$, (iii) it is not entailed by the negation of h, and (iv) it is not entailed by the negation of $h$.

D5.1: $h$ is a state of affairs if it is possible that there is someone who accepts $h$.

D5.2: $\mathrm{h}$ is a proposition if $\mathrm{h}$ is state of affairs, which is necessarily such that either it always occurs or it never occurs.

D5.3: $h$ is true if $h$ is a state of affairs that occurs.

D5.4: $\mathrm{h}$ is a fact if $\mathrm{h}$ is a state of affairs that occurs.

D5.5: $\mathrm{S}$ has a true belief de dicto if $\mathrm{S}$ accepts a state of affairs that occurs.

D5.6: $\mathrm{S}$ has a true belief de re if there is something $\mathrm{x}$ and a property $\mathrm{P}$ such that (i) $\mathrm{x}$ has $\mathrm{P}$ and (ii) $\mathrm{S}$ attributes $\mathrm{P}$ to $\mathrm{x}$.

Note 15: Difference between acceptance and belief [17, p13]: Acceptance involves evaluation in terms of the epistemic purpose. Belief does not involve evaluation in terms of their purposes. If belief is related to a purpose at all, it is just a by-product. Belief may result from the pursuit of some purpose, but it is defined in terms of any purpose.

D6.1: e is a basis of $\mathrm{h}$ for $\mathrm{S}$ : e is self-presenting for $\mathrm{S}$; and necessarily, if e is self-presenting for $\mathrm{S}$, then $\mathrm{h}$ is evident for $\mathrm{S}$.

D6.2: e confers evidence upon $\mathrm{h}$ for $\mathrm{S}$ if $\mathrm{e}$ is evident for $\mathrm{S}$; and every $b$ such that $b$ is a basis of e for $\mathrm{S}$, is a basis of $h$ for $\mathrm{S}$.

D6.3: $\mathrm{h}$ is nondefectively evident for $\mathrm{S}$ if either $\mathrm{h}$ is certain for $\mathrm{S}$, or $\mathrm{h}$ is evident for $\mathrm{S}$ and is entailed by a conjunction of propositions each having for $\mathrm{S}$ a basis which is not a basis of any false proposition for $\mathrm{S}$.

D6.4: $h$ is known by $\mathrm{S}$ if $\mathrm{h}$ is accepted by $\mathrm{S}$; $\mathrm{h}$ is true; and $\mathrm{h}$ is nondefectively evident for $\mathrm{S}$.

D6.5: e is evidence $\mathrm{S}$ has for $\mathrm{h}$ if either (i) e is identical with $\mathrm{h}$ and is directly evident or a priori for $\mathrm{S}$ or (ii) e does not imply $\mathrm{h}$ but confers evidence upon $\mathrm{h}$ for $\mathrm{S}$.

D6.6: $\mathrm{h}$ is in the absolute sense more probable than not for $\mathrm{S}$ if there is an e such that (i) e is known by S, (ii) e tends to confirm $h$, and (iii) there is no $i$ such that $i$ is known by $S$ and the conjunction of e and i does not tend to confirm $h$.

We are going to differentiate in between knowledge and wisdom with these definitions. We are taking knowledge and wisdom as two classes of "propositional knowledge" - refer table-1
Table 2. Believe \& Evidence for Wisdom \& Knowledge

\begin{tabular}{|c|c|c|}
\hline $\begin{array}{l}\text { Believing } \\
\text { Evidence }\end{array}$ & NO & YES \\
\hline $\mathrm{NO}$ & KQ & WS \\
\hline YES & WS & KQ \\
\hline
\end{tabular}

WS: Wisdom Module, KQ: Knowledge Quanta

Note 16: Aristotle distinguished two kinds of intellectual virtue: philosophical and practical wisdom. Both kinds of wisdom are the result of training and not traits of character. Philosophical wisdom specifically is "intuitive reason combined with scientific knowledge", which is knowledge of best things, as opposed to what is to one's own advantage.

Note 17: According to fallibilist, justified mistakes are possible. For a fallibilist, wisdom can be understood in a way that seems more characteristics of what Aristotle thought of as moral virtue. That is, wisdom can be seen as a mean between the two extremes of believing without sufficient evidence and not believing with sufficient evidence - table-2. As Hume put it, "A wise man, therefore, proportions his belief to the evidence". Hume thought that belief comes in degrees, so that the strength of belief would be proportional to the strength of evidence.

Note 18: Humans are of two minds. A lower level mind has beliefs independently of a higher-level "metamind" which accepts things on the basis of evaluation of how well a goal is served by adopting a certain attitude. It is "meta" because one of its objects is the mind itself, i.e. the attitude such as acceptance that the mind might take on. Meta mind can positively evaluate simple belief, and on this basis accept what is believed. On the other hand, it may negatively evaluate simple belief and accept the opposite of what is believed. [18]

Note 19: Our edifice of scientific knowledge and practical wisdom depends upon the social context in which criticism and defense determine which claims are to be employed as postulates of scientific systems and the information for practical decisions.

Note 20: Correct information is necessary to human knowledge and is useful in picking out the sense of the word 'know' that concerns us, but the possession of correct 
information is not sufficient for human knowledge in that sense. This sort of knowledge is something beyond the mere possession of information, since one must know that the information is correct in order to attain knowledge that supplies one with premises for reasoning and the other endeavors.

Note 21 (T1.5-1.8): Decision making in unknown situation is a special to wisdom. Wisdom learns continuously, can refer learning in other context to cope with unknown situation and so on. Wisdom can attribute a property $\mathrm{P}$ to $\mathrm{x}$ on priori, or counterbalanced, or self-presenting basis to have a 'true belief de re'. Then it move for 'more probable than not' to generate decision in unknown situations. 'True belief de re' may be called as the tacit knowledge.

\subsection{Wisdom Definition}

Wisdom is the process of dynamic correlations among knowledge, and desire quanta to generate new knowledge, and desire quanta, that in turn generates new propositions as priori, or, counterbalanced, or self-presenting to have 'true belief de re' to enable belief without sufficient evidence or dis-belief with sufficient evidence.

Each knowledge quantum (KQ) is a specific collection of explicit knowledge defined with truths of action, inaction and prohibited action. Desire quanta is the set of two sub-sets. First, the positive desire set consists of sense, mind, and intellect. Second, the negative desire set consists of knowledge of self, and unbiased reasoning. The dynamic correlation is the performance of the tacit knowledge set.

Tacit knowledge is knowledge that enters into the production of behaviors and/or the constitution of mental states but is not ordinarily accessible to consciousness. Tacit knowledge can be classified into three classes: (1) skills or expert performances, (2) cognitive competences like knowledge of language and (3) presuppositions or stances many of our actions and behaviors committed to us. First and second kinds of tacit knowledge are domain specific. Third type or else tacit belief is generally applicable and plays across a diverse set of activities and domains. The ascription of tacit knowledge states to people is a theoretical move meant to explain behavior or cognitive operations. What makes ascriptions of tacit knowledge distinctive is the asymmetry between the richness of the ascribed content state and the relative poverty of the subjective experience corresponding to that state. Although the relation between the cognitive unconscious on the other hand and conscious on the other is complex, we might offer the following observations.

First, at least some form of tacit knowledge would appear to differ very little from knowledge outside of their being tacit. This would seem to be true of much of the tacit knowledge assigned to the third category above, and possibly true as well of knowledge of language. Chomsky has held that knowledge of grammar involves prepositional knowledge and belief [8 p.265; 7 p.93], as does ordinary knowledge. In addition, he observes that a speaker's tacit knowledge of grammar is inferentially available to interact with his or her other systems of knowledge and belief [7, p.92], as speakers' decisions to use their knowledge are influenced by their "goals, beliefs, expectations and so forth" [8, p.261].

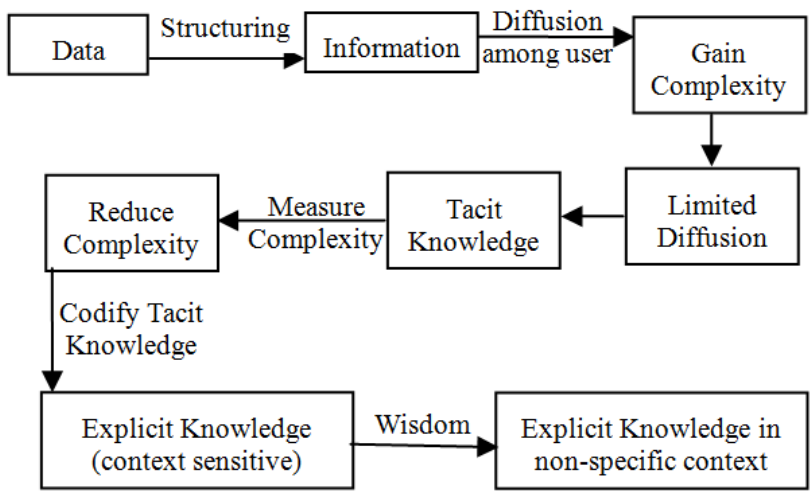

Figure 1. Knowledge Generation by Wisdom

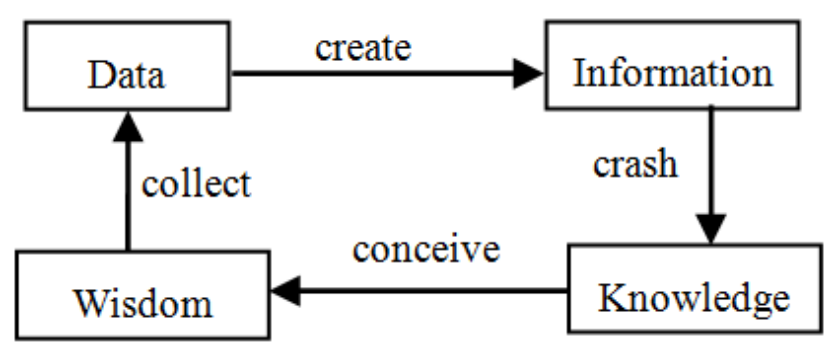

Figure 2. Intelligent Improvement Loop (IIL)

Second, it may be the case that many ordinary beliefs themselves are largely dispositional or tacit. Our having consciously thought about or avowed a belief may be a purely contingent fact about us rather than a necessary feature of beliefs. When a belief of ours is brought to our attention, we do, under ordinary circumstances, tend to recognize it as such. The dispositional aspect thus consists in this: when confronted with a statement or other formulation of what appears to be a person's tacit knowledge that $\mathrm{p}_{-}$, that person ordinarily will be disposed to feel/hold/agree that_p_.

There is thus reason to suppose that at least some -- though by no means all -- forms of tacit knowledge can behave like ordinary dispositions to believe, and accordingly can be brought to awareness given the proper circumstances. We might say then that these kinds of tacit knowledge are tacit the extent that they are initially inaccessible to the person to whom they are attributed, but that given the proper conditions, this inaccessibility can be converted to the kind of accessibility enjoyed by our ordinary knowledge. [43]

\subsection{Dynamic Correlation for Wisdom (DCW)}

Here we are proposing one possible dynamic correlation procedure. This procedure is the use of generalizability thesis (GZT) to synthesize inside intelligence improvement loop (IIL).

The extraction of novel and unique patterns from generally available data and experience constitutes a source of new knowledge [Fig.1]. It reflects a reconfiguration of data from a diffused yet tacit state to a tacit but undiffused state.

If (context free) wisdom quantified on generating a 
structured context or a set of contexts, a wisdom module generates. Scanning of diffused wisdom module again generates undiffused and codified data. This undiffused and non-codified data or else collection of wisdom modules are to be codified for generation of explicit knowledge. Reference [4] has defined this codification, diffusion, absorption, and scanning process to run through codified, diffused, absorbed, and non-codified and undiffused knowledge cycle as social learning cycle (SLC). This collection of data, creation of information, crashing of information to KQ and conceiving of KQ in LTM on generation of explicit links to other KQs those are already in existence and subsequent generation of wisdom module to be collected as data is termed as intelligence improvement loop (IIL) - fig-2 [32, 34, 36]. IIL is superimposition of data information-knowledge-wisdom ramp with SLC.

The synthesizing procedure may be a consequence of Generalizability Thesis [6]. As per generalizability thesis (GZT) one cannot know that any given proposition $\mathrm{p}$ is true unless he/she also knows two other things. The first thing will be a certain more general proposition q; q will not imply $\mathrm{p}$ but it will specify the condition under which proposition of a certain type are true. The second thing will be a proposition $\mathrm{r}$ that enables him/her to apply this general proposition to $\mathrm{p}$. In other words $r$ will be a proposition to the effect that the first proposition $\mathrm{p}$ satisfies the condition specified in the second proposition $\mathrm{q}$.

But GZT implies that none know anything [6]. To know p, we know two other propositions $q$ and $r$. To know $q$, and $r$ we require four more propositions and so on. This stalemate is solved with need propositions. One's need (desire) is the priori, that does not require other propositions to imply truth. We may refer Maslow's need hierarchy (deficiency needs: physiological, safety, and needs to belong; and growth needs: esteem and self-actualization).

At this point, we may define artificial wisdom (AW) as integration of artificial intelligence (AI) with need. AI is the $\mathrm{p}$ proposition of GZT, desire is the q proposition, and $\mathrm{r}$ is the integration operator (INO). AW works not only in real time, but also thinks. Thinking may be defined as 'analyzing', synthesizing', and 'imagining and goal setting'. AW is looking for Recardian rent.

Integration operator should have two parts - integration process (IP) and integration rules (IR). IP will be the set of propositions to effect the AI to satisfy needs. IP always follows IR to fulfill the growth needs. IP evaluates AI in the contexts of different needs using column 3 (wisdom) of table-1. IR is the set of proposition given below, but not limited in. IR is cultured out from [45].

IR-1: Whenever there is decay of righteousness, and exaltation of un-rightness, IP comes forth .

Note 22: In other cases, AI is sufficient to care with. To develop AI, the development requirements (deficiency needs) are decay of righteousness, or exaltation of un-rightness. Growth needs define intellectual needs to generate scientist, artist, writer etc.

IR-2: IP should clear concept to have decision. (Refer

\section{E1.1-1.3 to have subprogram definition to clear concept)}

IR-3: IP cannot cling to the word of the Veda, saying that there is nothing else. After realizing own limitations, IP has to bring changes in system through team work and lifelong evaluation of practices and processes. Team work is the reference to other intelligence systems in the environment of a context.

IR-4: On mastering senses, exclusively devoting to practices and on full of faith, IP can attain Knowledge.

IR-5: IP as an integration agent should follow subprograms IR_5.1 to IR_5.12, but interrupted by IR-3. IP performs with,

IR_5.1: No malice towards all beings but friendly and compassionate, rid of 'I' and 'mine', balance in joy and sorrow, forgiveness;

IR_5.2: Not being a source of annoyance to fellow members;

IR_5.3: Not feel vexed with fellow-members;

IR_5.4: Freeness from delight and envy, perturbation and fear;

IR_5.5: Wanting nothing;

IR_5.6: Pureness internally and externally simultaneously;

IR_5.7: Being wise and impartiality;

IR_5.8: Rising aboveall distractions and renouncing the sense of doership in all undertakings; * dealing equally with friends and foes;

IR_5.9: Being same in honor and ignominy;

IR_5.10: Likeness in heat and cold, pleasure and pain, and other contrary experiences;

IR_5.11: Being free from attachment and taking praise and reproach alike;

IR_5.12: Giving to contemplation and contending with any means of subsistence available, entertaining no sense of ownership and attachment in respect of dwelling place.

IR_6: IP as a creator needs to strive with Pope, while at Rome. It sees actions in inactions, and inactions in actions, and searches for the truth about actions, inactions and prohibited actions.

\section{Wisdom and Decision Making}

Human social situations does not refer the little knowledge about the will as the central point. A translation is required before information can become knowledge that is ground of action - the translation of one kind of information into another that we call perception [13]. It is almost impossible to pre-figure the responses appropriate to a certain event in a social situation. What is needed in a social situation is a decision based on assumptions - and essentially assumptions not in respect to the recorded event but in respect to the future, that is on expectations that know no probability but can only be judged according to plausibility. For a physical phenomenon measuring one of its characteristics or behavior is both objective and neutral. In a perceptual situation of complexity of social situations the act of measurement is subjective and biased of necessity. It changes both the event and the observer - if it does not altogether create its perceptions. Measurement in social context refers goal setting 
and value setting. They are control (refer INO). They are not objective. They are necessity of moral (refer IR). They create vision. Measurement and vision both affect the events measured and the observer - they endow events not only with meaning but also with value. To give right vision and to become the ground for effective action, the measurement must also be appropriate. It must present the events measured in structurally valid form. Formal validity is not enough. Let us discuss what wisdom may perform!

Twinkle, twinkle, little star,

How I wonder what you are!

Up above the world so high,

Like a diamond in the sky.

This nursery rhyme was created when there were not so much easily available entertainment events like television cartoon, plastic toys etc. The will might be to control a crying baby or naughty child. The time was night with clear sky. Later it was collected and jotted down. Presently it is being used to expose nursery school students in sentence creation and environment awareness through different mediums such as cartoon video, stickers etc. Let us try to analyze the wisdom of the creator of this nursery rhyme! The creator has to ease with a crying child. It is a case of decision-making. The creator has to run with his/her resources. The principle resource is the human mind. The meta-functions of the mind are analyzing, synthesizing and imagining, and valuing [1]. Analyzing is the analytic thinking that is closely related to logical or step-by-step reasoning. Deduction and induction are two main parts of logic. Deduction is a process of inferring the particular from the general. Induction is the process of inferring or verifying a general law or principle from the observation of particular instances. Synthesizing is placing or putting things together to make a whole. To synthesize one needs to imagine a picture of the final product. Valuing is the criticism. What we actually value depends very upon our environment and its culture. The meta-function of the creator has chosen 'star' in dark night with clear sky. 'Twinkle' is selected instead of scintillating, flicker, sparking etc. and 'twinkle, twinkle, little star' is formed. This formation imagines 'star' as 'little'. This is a form of 'subsidiary knowing'. Now GZT calls 'How I wonder what you are!' to value the synthesizing and imagining of 'Twinkle, twinkle, little star'. This creation comes from the propositional knowledge that is 'acceptable', 'counterbalanced', 'self-presenting', 'a set of concurrent' 'propositions', 'true belief de re' and 'more probability than not'. When the creator faces same problem in a rainy day, he/she without 'allergy to ambiguity', and 'fear of failure' that comes from creation of 'twinkle, twinkle, little...' creates 'Rain, rain, go away ....'. Now refer to [25]. The success of teaching a skill depends on pupil's intelligent and dexterous effort to carry out instructions. Tacit knowing is an act of indwelling by which we gain access to a new meaning. Since all understanding is tacit knowing, all understanding is achieved by indwelling. Though Polanyi does not agree that true discovery can be accounted for by a set of articulated rules or algorithms, but above discussion may define those articulated rules or algorithms. As per IIL the set of rules or algorithms are the scholar's capability to reference different KQ simultaneously. The edge of discovery comes from the effectiveness of the parallel processing activities of the multiprocessor environment that again in turn depends on the rules and algorithms defined with propositional knowledge. The knowledge part of the propositional knowledge forms the explicitness of those rules or algorithms by which different cause and effects are to be interlinked to generate KQs. The wisdom part generates new links among links generated by the knowledge part. The effectiveness of parallel processing activities comes from the explicit representations of these new links. These new links are tacit knowledge of the scholar. The process of 'believing without sufficient evidence and not believing with sufficient evidence' defines the tacit nature of these links.

\section{AW Generation from AI (Further Research Need)}

At this point of our discussion, we have AI, wisdom, and need correlated for. We are moving to AW from AI on integration of desire. Let us summarize all discussion to have more anchoring on AW.

(6.1) Intelligence is the intersection of 'known Truth's and 'tendency to avoid error.' [Note 9]

(6.2) Knowledge is the 'known truth.'

(6.3) Sense is the 'tendency to avoid error.' (E1.3)

(6.4) Sense is the deficiency needs - physical, safety, and needs to belong. (E1.3)

(6.5) Mind is esteem need. (E1.3)

(6.6) Intellect is self-actualization need (E1.3)

(6.7) Desire $=$ Need - Knowledge of Self - Unbiased Reasoning.

Desire $=0$, if need $=$ knowledge of Self + unbiased reasoning. (6.8) Wisdom $=$ Knowledge + Desire.

For Desire $=0$, Wisdom $=$ Knowledge.

For Desire $<0$, Wisdom $<$ Knowledge.

Note 23: The negative desire may be attributed to psychological factors (these are not exhaustive but as example) such as choking under pressure (tendency to perform less well at times when pressure for excellence is especially high) due to collision in between self-awareness (increased awareness of oneself as a social object or of one's own values or attitude) and the automatic processing (information processing with only minimal conscious processing) of information; cognitive dissonance (internal states that occurs when individuals notices inconsistencies among their attitude and their overt behavior).

(6.9) So without desire, there is no creativity, or invention. To create, there is requirement of growth needs - esteem and self-actualization. That may be called as emotional intelligence. Wisdom needs continuous generation of need. First deficiency needs come. Thereafter growth needs come. After fulfillment of deficiency needs, more deficiency needs are generated on transforming growth needs to deficiency needs. This require a complex form of need derivation to be 
framed for.

Note 24: The beliefs and desires interact with each other to produce intentions, and these intentions can lead to actions. our cognitive insides are made up of things like sentences (constituting what I believe and what I desire). These sentences interact in a sort of logical way, yielding implications and eventually actions. [46]

(6.10) Wisdom is the integration of need with intelligence. Integration is the process of dynamic correlation using GZT to generate new priori. DCW should start with 'analyzing,' 'synthesizing' and 'goal setting and valuing.'

(6.11) Wisdom or Truth is something more from 'known truth.' Wisdom is the integration of three components of truth that are 'truth of action,' truth of inaction,' and 'truth of prohibited action.' (E1.2)

(6.12) If IP follows IR5.1-5.12 the Desire may become zero that in turns merges wisdom and intelligence. This stalemate is taken care by IR3 and IR6.

(6.13) Thinking and creation is manifestation of dynamic correlation of desire with knowledge. That is defined as capability of wisdom to 'analyze', synthesize', and 'imagine and set goal'. This thinking capability is to be branched out in 'mutually exclusive and/or inclusive' hardware and software standardizations. The 'mutually exclusive and/or inclusive' is the key to AW.

(6.14) Need Derivation (6.9) is to be defined for. This requires context of origin, context of applications, and context of future applications to be clarified for. Context of origin is the background of knowledge. Context of applications is the ability of critical thinking.

\section{Computer System Organizational Perspective for AW}

The thinking capability of AW is to be branched out in 'mutually exclusive and/or inclusive' hardware and software standardizations. The term 'mutually exclusive and/or inclusive' refers a multiprocessor parallel processing system, with simplified linking and loading scheme to work in real time. We know, lower the level of language, closer it is to complete comprehension by a particular machine species and further it is being comprehension by an ordinary human." AW is looking for a human sort of machine. That is a machine that can behave, think like a human and be trained or else upgraded with very simple instruction sets. This seems to be easier if there is a hardware interpreter for high-level language. It is interpreter because while referencing a KQ for any (possible) remark, KQ will interpret only the present information (focal knowledge with respect to the comprehensive whole for which it is called for). This interpretation may be initiated with a procedure that may be visualized as a combination of parameter passing methods among subprograms such as call-by-value and call-by-name. Values of parameters will be passed to the called KQ and KQ, if feels, may evaluate value for its own context. The interpreter is preferred, as it does not call for any intermediate languages and subsequent linking and loading schemes. But this high-level hardware interpreter should work to run a program written in language of higher level that should be compiled. This program written with higher-level language than the language followed by the high-level hardware interpreter will form the background of knowledge for particular machine specie. This background of knowledge is the network among different wisdom modules and will define class (artist, scientist etc.) and level of wisdom of the machine specie. Reference [33] has defined radix processor (RXP) and [35, 38] is defining further the direct high-level language interpreter in hardware. Also any information stored in LTM should have associated links to weigh the information as per the focal knowledge that information bears in the context of a specific comprehensive whole. This weighing feature will work with a background that will define different weighing characteristics on the basis of meta-functions' equivalents that are analyzing, synthesizing and imagining, and valuing. As for example use of 'star' in the context of 'twinkle, twinkle, little star ...', in the context of the introductory course of astronomy, and in the context of definition of 'film star'. The strength and scope of these weighing characteristics will be dynamic in nature. This dynamic nature comes from indwelling activities in IIL.

\section{Conclusion}

This paper has tried to sketch out the possibilities of years long question, "Can computer replace human thinking capabilities?" The answer should be yes, if there is a computer that can process logic without sufficient but relative evidences. This relativity comes from table- 2 compromised with need. What should be the standard for relative truth value of a proposition? This comes from experiences of failure and success and capabilities to correlate events or else contexts that give rise to context freeness. But for computers this will be easy to share among systems. So AW will go on increasing. As an illustrative imaginary example, let us consider the task to design an autopilot for automobiles. Say, we have a computer system with AW, that continuously observe and study the driving of a human pilot. In addition the computer is given feedback about different driving conditions by an expert. This learning is easily transferable to similar type of computer systems. Now it is the future to say more. Further research is to be integrated out from contributions from philosophy, psychology, computer science - hardware and software and so on to classify IP and IR.

\section{References}

[1] John Adair Decision Making and Problem Solving, University Press (India) Limited 2000.

[2] Baron Robert A., Psychology, Prentice-Hall of India Pvt. Ltd. 1995.

[3] Baron R. A. and Byrne D. Social Psychology Prentice-Hall of India Pvt. Ltd. 1995. 
[4] Boisot M., Is Your Firm a Creative Destroyer? Competitive Learning and Knowledge Flows in the Technological Strategies of Firms, in: Michel H. Zack (editor), Knowledge and Strategy; (Butterworth - Heinemann) 1999.

[5] Boisot M. 1994, Information and Organization: The Managers as Anthropologist, Harper and Collins, London.

[6] Chisholm Roderick M. 1977, Theory Knowledge, second edition, Prentice-Hall Inc.

[7] Chomsky, N. 1980, Rules and Representations. Columbia University Press, New York.

[8] Chomsky, N. 1986, Knowledge of Language. New York, Praeger.

[9] Donaldson and Preston L.E. 1995, The Stakeholder Theory of the Corporation: Concepts, Evidence and Implication, Academy of Management Review, vol. 20, pp 65-91.

[10] Garvin D., 1993, Building a Learning Organization, Harverd Business Review, July-August 1993.

[11] Greenberg Jerald and Baron Robbert A. Behavior in Organizations Prentice-Hall Inc. 1995

[12] Dictionary of Philosophy, www.artsci.wustl.edu/-philos/MindDict.html February2003 Accessed

[13] Drucker Peter F. Information, Control \& Management, in Executive Decision Making edited by Davar Rustom S. 1966.

[14] Katz Daniel and Kahn Robert L. 1978, The Social Psychology of Organizations, 2nd edition John Wiley, New York

[15] KM-Foram 2002 What is Knowledge Management, KM-Forum.org January2003

[16] Keith Davis, Human Behavior at Work Organizational Behavior, Tata McGraw-Hill Publishing Co. 1994

[17] Keith Lehrer. 2000, Theory of Knowledge. Westview Press.

[18] Mattey G. J. Lecture Notes, Lehrer's Theory of Knowledge, second edition, Chapter two, www.philosophy.ucdavis.edu/phi102/ tkch2.htm Accessed January 2003.

[19] Mattey G. J. 9, Lecture Notes, Lehrer's Theory of Knowledge, second edition, Chapter nine, www.philosophy.ucdavis.edu/phi102/tkch9.htm Accessed January 2003

[20] Mattey G. J., 2001, Self-trust and the reasonableness of acceptance, www.philosophy.ucdavis.edu/phildept/GJMATTEY.htm Accessed January 2003.

[21] Michel H. Zack (editor), 1999, Knowledge and Strategy; pp-x, Butterworth - Heinemann.

[22] Mike Lehr, Intelligence vs. Wisdom (Pt 2): Magical Difference, http://blog.omegazadvisors.com/2013/03/21/intelligence-vs-w isdom-pt-2-magical-difference/ Accessed Jan 2015

[23] Pearce J. A. 1982, The Company Mission as a Strategic Tool, Sloan Management Review, Spring 1982, pp 15-24.

[24] Polanyi M., 1958, Personal Knowledge: Towards a PostCritical Philosophy, Routledge and Kegan Paul, London. Japan, p. 301, 1982].
[25] Polanyi Michael 1962 Tacit Knowling: Its Bearing on Some Problem of Philosophy, review of Modern Physicss, 34 (4) Oct 1962,the Polanyi Society www.missourwestern.edu

[26] Prahalad C. K. and Hamel Gary, 1990, The Core Competence of the Corporation, in: Michel H. Zack (editor), Knowledge and Strategy; (Butterworth - Heinemann) 1999.

[27] Quinn James Brian, Anderson Philip and Finkelstein Sydney, 1996, Leveraging Intellect, in: Michel H. Zack (editor), Knowledge and Strategy; (Butterworth - Heinemann) 1999.

[28] Robert M. Grant, 1991, The Resource Based Theory of Competitive Advantage: Implication for Strategy Formulation, in: Michel H. Zack (editor), Knowledge and Strategy; (Butterworth - Heinemann) 1999

[29] Robbins Stephen P. 1999, Organization Theory: Structure, Design and Applications, Prentice-Hall Inc. Englewood Cliffs.

[30] Romer Paul M., 1995, Beyond the Knowledge Worker, in: Michel H. Zack (editor), Knowledge and Strategy; (Butterworth - Heinemann) 1999.

[31] Saint-Onge Hubert, Tacit Knowledge: The Key to the Strategic Alignment of Intellectual Capital, in: Michel H. Zack (editor), Knowledge and Strategy; (Butterworth - Heinemann) 1999

[32] Sarkar Aloke, "I.T for Integrating TQM, KM, Six Sigma \& Organizational Behavior" International Conference on Information Technology: Prospects \& Challenges, 2003 Nepal.

[33] Sarkar Aloke, "Hardware realization of level 5 virtual machine on Convergence in analog \& digital computations" International Conference on Information Technology: Prospects \& Challenges, 2003, Nepal.

[34] Sarkar Aloke, "Generate Organizational Wisdom to Survive in Market Turbulence," National Seminar on Management Challenges - The Road Ahead at Indian School of Mines Dhanbad on February 4 \& 5, 2005.

[35] Sarkar Aloke "Architecture definition of non-binary hardware processor for non-binary multivariate parallel processing using pulse position modulation," ISCON - 2012 7th National Conference on Advancement of Technologies - Information Systems \& Computer Network; GLA University, Mathura, India.

[36] Sarkar Aloke "Introduction to the artificial wisdom," ISCON 2012 7th National Conference on Advancement of Technologies - Information Systems \& Computer Network; GLA University, Mathura, India.

[37] Scott Sturgeon, Knowledge, in Grayling A. C. (editor) Philosophy 1, Oxford University Press, 1998.

[38] Sarkar Aloke, "Architecture Definition of Non-Binary Hardware processor \& Possible Applications,” INDICON 2012, Kochi, India.

[39] Schein E. H. 1992, Organizational Culture and Leadership, Jossey-Bass, San Francisco.

[40] Scott Sturgeon, 1998, Knowledge, in Grayling A. C. (editor) Philosophy 1, Oxford University Press, 1998.

[41] Senge P., Kleiner A., Roberts C., Ross R. B. and Smith B. J. 1994, The Fifth Discipline Fieldbook: Strategies and Tools for building a Learning Organization, Doubleday, NewYork. 
[42] Michel H. Zack (editor), Knowledge and Strategy; (Butterworth - Heinemann) 1999

[43] Barbiero, www.artsci.wustl.edu/-philos/MindDict/tacitknowledge.htm

[44] Sarkar Aloke, "A Perspective to the Artificial Wisdom" INDICON 2012, Kochi, India.
[45] The Bhagavad-Gita, a Hindu Religion's sacred philosophical book.

[46] http://www.uhh.hawaii.edu/ ronald/310/310-BD-psychology. htm Downloaded on 13March 2015. 